\title{
PENGEMBANGAN KETAHANAN KEAUSAN PADA BAHAN KAMPAS REM SEPEDA MOTOR DARI KOMPOSIT BONGGOL JAGUNG
}

\author{
Pramuke Ilmu Purboputre \\ Program Studi Teknik Mesin, Fakultas Teknik, \\ Universitas Muhammadiyah Surakarta \\ H.A. Yani Tromol Pos 1 Pabelan, Kartasura
}

\begin{abstract}
ABSTRAK
Penelitian ini memanfaatkan bonggol jagung sebagai serat pengisi. Bonggol jagung dalam hal ini sebagai serat penguat kanena termasuk serat alam yang limbainya banyak tidak dipergunakan. Matriks yang digunakan adalah polyesester. dengan serat campuran fiberglass.

Metoda pembuatannya dengan cara pengepressan dan sintering pada suhu $180^{\circ} \mathrm{C}$. Pengujian yang dilakukan adalah pengujian kekerasan, impak dan keausan.

Hasilnya adalah Unsuk Pengujian Keomsan Ogashi pada kandisi kering, maka bahan kampas rem mempunyai nilai keausan yang paling rendah yaitu sebesar $0.0004 \mathrm{Imm}^{2} / \mathrm{kg}$, yang sedikit lebih besar dari produk di pasaran dengan keausan sebesar 0.00014 mm $\mathrm{mm}^{2} \mathrm{~kg}$. Untuk Pengujian Keausan Ogoshi Kondisi basah dengan air, diperoleh bahwa, bahan kampas rem paling rendah keansannya yaitu sebesar $0.0062 \mathrm{~mm}^{2} / \mathrm{kg}$, namun masih lebih tinggi sedikit dari bahan kampas rem pasaran (eksipart) yaitu sebesar $0,0032 \mathrm{~mm}^{2} / \mathrm{kg}$
\end{abstract}

Kata Kunci: serat bonggol jagung, polyester, keausan.

\section{PENDAHULUAN}

Pemakaian kampas rem biasanya tidak lebih dari 10000 kali kontak pengeraman, artinya pengyunaan dalam kota bisa jadi tidak lebih dari 6 bulan, apalagi terjadi keluhan umuryang lebih pendek akibat kampas rem ausnya tidak rata, sehingga pengereman tidak efektif atau tukar tukar adaptor rem.

Keausan tidak merata bisa diakibatkan tekanan yang kurang seragam, akibat pemasangan yang kurang tepat, misalnya terlalu kencang pada pinnya, sehingga pin bukan berfungsi sebagai pin, tetapi sepagai titik putar yang mati (Gustav Niemann, 1981).
Kekuatan bahan komposit partikel rem, sangat dipenganuhi besar partikel, bahan matriknya dan proses pembuatannya. Kekuatan komposit partikel diperoleh maksimal pada ukuran 0,01 sampai 0,1 mm dan kekuatan surface bonding, pengepresan, dan sintering ( Calister, 2005). Proses tersebut sangat jarang dipaparkan para produsen kampas rem, sehingga perlu adanya penelitian tentang : bahan dan proses yang standar secara ilmiah agar kampas rem bisa mudah dibuat di negara kita, sehingga sangat perlu pengembangan penelitian ini secara terus menerus.

Penelitian ini menggunakan bahan bonggol jagung, fiber glass, dan serbuk alumuniam (Al) 
bermatriks polyester akan diuji kekuatannya dengan metode pengujien kekuatan gesek ( $O$ goshi) dan pengujian kekuatan kekerasan (Brinell). dan juga foto makro, dan pengujian karakteristik pengeremannya. Variasi komposisi ditentukan sebagaiberikut.

1. Variasi 1: komposisi sebesar $40 \%$ bonggol jagung $+10 \%$ fiber glass $+10 \%$ aluminium $(A l)+40 \%$ polyester.

2. Variasi 2: komposisi sebesar $30 \%$ bonggol jagung $+15 \%$ fiber glass $+15 \%$ aluminium (Ai) $+40 \%$ polyester.

3. Variasi 3: komposisi sebesar $20 \%$ bonggol jagung $+20 \%$ fiber glass $+20 \%$ aluminium (Al) $+40 \%$ polyester.

\section{Rumusan Masalah:}

Keausan tidak merata bisa diakibatkan tekanan yang kurang seragam, akibat pemasangan yang kurang tepat, misalnya terlalu kencang pada pinnya, sehingga pin bukan berfungsi sebagai pin , tetapi scbagai tifik putar yang mati, dan adanya kontribusi ketahanan aus dan kekerasan bahan rem.

Kckuatan bahan komposit partikel rem, sangat dipengaruhi besar partikel, bahan matriknya dan proses pembuatannya. Kekuatan komposit partikel diperoleh maksimal pada ukuran 0,01 sampai $0,1 \mathrm{~mm}$ dan kekuatan surface bonding , pengepresan, dan sintering ( Calister, 2005). Proses tersebut sangat jarang dipaparkan para produsen kampas rem, sehingga perlu adanya penelitian tentang : bahan dan proses yang standar secara ilmiah agar kampas rem bisa mudah dibuat di negara kita, sehingga sangat perlu pengembangan penelitian bahan kampas rem ini secara terus menerus.

\section{Tujuan Penelitian}

Dalam penelitian ini bertujuan untuk:

1. Mengembangkan tingkat keausan bahan kampas rem, dengan menggunakan variasi komposisi dari serat bambu, fiber glass, serbukaluminium $(A l)$, dengan matriks polyester, dengan hasil terbaik kekerasan dan keausan pada komposisi : a. $40 \%$ bonggol jagung $+10 \%$ fiber glass $+10 \%$ aluminium $(A D)+40 \%$ polyester

b. $30 \%$ bonggol jagung $+15 \%$ fiber glavs $+15 \%$ aluminium $(A l)+40 \%$ polyester

c. $20 \%$ bonggol jagung $+20 \%$ fiber glass $+20 \%$ aluminium $(A i)+40 \%$ polyester. yang akan dijadikan prototype kampas rem sepeda motor.

2. Mencliti karakteristik pengeremannya, dengan uji dynamometer, sehingga diperoleh parameter pencgereman, daya serap pengereman, jarak penegereman, koefisien gesek kampas rem. Pada variasi pengujian koefisien gesek, pada keadaan kering (udara) dan keadaan basah ( air dan oli)

\section{Keutamaan Penelitian}

Melakukan penelitian terapan yang hasilnya diharapkan secara jangka panjang di negara Indonesia agar tidak ketergantungan lagi dengan komponen mesin dari huar terutama kampas rem, dan sekaligus memanfaatkan daur ulang dan potensi alam yang ada di lingkungan sekitar kita serta lebih aman bagi kesehatan.

\section{Tinjauan Pustaka}

Irfan, Pramuko IP, Ngafwan (2009), melakukan penelitian tentang kampas rem gesek dengan memberikan waktu sintering pada tekanan kompaksi sebesar 10 menit. Keausan suatu bahan komposit semakin besar atau semakin mudah aus dapat dipengaruhi oleh besarnya waktu yang diberikan pada proses kompaksi. Bilu waktu penekanannya semakin besar maka tingkat keausan pun juga semakin besar. Nilai kekerasan suatu bahan juga terpengaruh oleh besar waktu penekanan kompaksi yang diberikan dalam proses pembuatan bahan kampas rem. Dalam pembuatan kampas, nilai kekerasan kampas juga berpengaruh dengan semakin besar kompaksi yang dibebankan maka semakin keras pula komposit tersebut. Karena komposit tersebut sendiri dipengaruhi oleh beberapa faktor dalam proses pembuatan dari bahan menjadi komposit dan beberapa penyebabnya yaitu: variasi bahan, beban kompaksi yang diberikan ser- 
ta lamanya beban kompaksi, dan pemanasan (sinter).

Masmui (2003), Berdasarkan prosiding seminar teknologi untuk negeri menyatakan bahwa karakteristik dengan tingkat keausan rendah dan Brinell Hardiness Number ( $B H N$ ) tinggi diperoleh dengan memberikan tekanan pembentukan relatif lebih rendah dibanding spesimen lainnya. Hal ini disebabkan olch dua kemungkinan:

1. Terpisahnya resin sebagai bahan pengikat (binder) dari campuran komposit.

2. Kekuatan ikat resin lebíh kecil dari pada tekanan pembentukan yang diberikan pada specimen pada waktu proses pembuatan spesimen.

Imam, Pramuko I.P (2009), melakukan penelitian tentang kampas rem gesek dengan memberikan peningkatan sintering. Dengan semakin tinggi suhusintering berpengaruh pada tingkat keausan. Jika semakn tinggi suhu sinteringnya maka menyebabkan nilai keausan meningkat. Maka keausan semalkin tinggi. Peningkatan suhu sintering juga berpengaruh pada kekerasan kampas. Semakin tinggi suhu sinteringrya maka nilai kekerasarmya akan semakin menunin.

Nanang (2005), Bahan komposit sebenarnya banyak sekali terdapat di alam, karena bahan komposit bisa terdiri dari organik dan anorganik seperti bambu, kayu, daun, dan sebagainya. Secara tidak sadar sebenarnya kita telah mengenal berbagai jenis komposit. Seseorang memperkuat tanah liat dengan jerami, merupakan komposit yang sudah lama dikenal.

\section{Landasan Teori}

Keausan pada kampas rem berbanding lurus dengan tekanan operasional dan kecepatannya:

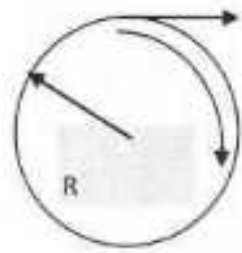

Aus Kampas berbanding lurus dengan $\longrightarrow$ p.v v

$\mathrm{p}=$ tekanan permukaan;

$\mathrm{v}=$ kecepatan operasional gesekan

$v=w \cdot R ; w=$ kecepatan sudut roda

$\mathrm{R}=$ Jari-jari roda

Syarat bahan kampas rem:

- kekerasan kampas rem harus lebih rendah dari kekerasan tromol remnya

- Tidak mudah panas

- Tahanan geseknya besar

- Tahan aus

Tabel harga-harga koefisien gesek beberapa bahan kampas rem ditunjukkan pada Tabel 1.

\section{Proses Kompaksi}

Proses kompaksi adalah proses memampatkan serbuk sehingga serbuk akan saling melekat dan rongga udara antar partikel akan terdorong ketuar. Semakin besar tekanan kompaksi jumlah udara (porositas) diantara partikel akan semakin sedikit, namun porositas tak mungkin mencapai nilai nol. Hasil kompaksi biasa discbut Green Body. Proses pemampatan adalah suatu proses mesin kompaksi yang memberikan gaya penekanan uniaksial (German, 1984). Pemberian tekanan yang sangat besar terhadap material serbuk yang bertujuan untuk mendapatkan spesimen benda uji yang diinginkan.

\section{Sintering}

Istilah sintering berasal dari bahasa Jerman, "sinter" dalam bahasa Inggris seasal dengan kata "cinder" yang berarti bara. Sintering merupakan metode pembuatan material dari serbuk dengan pemanasan sehingga terbentuk ikatan partikel. Sintering adalah pengikatan bersama antar partikel pada suhu tinggi. Sintering dapat terjadi dibawah suhu leleh (meiting point) dengan melibatkan transfer atomic pada kondisi padat. 
Tabel 1. Karakteristik bahan - bahan kampas rem

\begin{tabular}{|c|c|c|c|c|c|}
\hline \multirow{2}{*}{$\begin{array}{l}\text { Group } \\
1\end{array}$} & \multirow{2}{*}{$\begin{array}{l}\text { Friction Pairing } \\
\text { Grey cast aron, cast steel or steel with: } \\
\text { Phenotic Plastic } \\
\text { Cotton-plastic } \\
\text { Astestos-plastic } \\
\text { Pressed Astestos-plastic } \\
\text { Pressed Metal fibre-Buna } \\
\text { Graphit carboon-ateel }\end{array}$} & \multicolumn{2}{|c|}{$\begin{array}{l}\text { Coefiaient of Fricion } \\
\text { Dry wet }\end{array}$} & \multirow{2}{*}{$\begin{array}{c}\begin{array}{c}\text { Opentional } \\
\text { temperature } \\
\text { ("C) }\end{array} \\
\\
100-150 \\
100-150 \\
200-300 \\
250-500 \\
250-300 \\
300-550\end{array}$} & \multirow{2}{*}{$\begin{array}{c}\text { Operntional } \\
\text { Pressure } \\
\text { (keffem2) }\end{array}$} \\
\hline & & $\begin{array}{l}0,25 \\
0,4-0,65 \\
0,3-0,5 \\
0,2-0,35 \\
0,4-0,65 \\
0,25\end{array}$ & $\begin{array}{l}0,1-0,15 \\
0,1-0,2 \\
0,1-0,2 \\
0,1-0,15 \\
0,1-0,2 \\
0,05-0,1\end{array}$ & & \\
\hline u & $\begin{array}{l}\text { Grey cast iron, cast stcel or steel with: } \\
\text { Popplar wood Leather }\end{array}$ & $\begin{array}{l}0,2-0,35 \\
0,3-0,6\end{array}$ & $\begin{array}{l}0,1-0,15 \\
0,1-0,15\end{array}$ & $\begin{array}{l}100-150 \\
100\end{array}$ & $\begin{array}{l}0,5-5 \\
0,5-3\end{array}$ \\
\hline III & Hard steel-hard steel & $0,12 \cdot 0,17$ & $0,06-0,11$ & 100 & $5-30$ \\
\hline IV & Stect-Graphite & $0,4-0,5$ & & 300 & \\
\hline v & Grey Cast Iron-steel & $0,15-0,2$ & $0,03-0,06$ & 300 & $8-14$ \\
\hline
\end{tabular}

Bahan-bahan Pembentukan Komposit

\section{Bonggol Jagung}

Jagung adalah tunuhan monocotil yang buahnya menempel pada boll/ janggel jagung Janggel jagung temasuk bahan sclulosa yang bisa menyerap air namun mempunyai sifat cukup kesat. Kandungan air pada bonggol jagung antara 50\%-99\%. Berat Jenis : $0,9 \mathrm{kgf} / \mathrm{dm}^{3}$

\section{Fiber Glass}

Fiber glass dalam bahan komposit berperan sebagai bagian utama yang menahan beban, sehingga besar kecilnya kekuatan bahan komposit sangat tergantung dari kekuatan serat pembentuknya. Semakin kecil bahan (diameter serat mendekati ukuran kristal) maka semakin kuat bahan tersebut, karena minimnya cacat pada material.

\section{Aluminium (A)}

Aluminium (Al) merupakan logam ringan yang mempunyai ketahan korosi yang baik dan hantaran listrik yang baik dan sifatsifat yang baik lainnya sebagai logam. Serbuk aluminium (Al) yang disinter memiliki sifat yang berbeda dengan kebanyakan jenis material yang lainnya.

\section{Matriks (Polyester) dengan Katalisnya.}

Fungsi matriks adalah sebagai pengikat serat, transfer beban dan pendukung serat. Pada komposit serat (Fibrous Composites) matriks yang digunakan adalah resin (plastik yang berfasa cair). Matrik polyester paling banyak digunakan terutama untuk aplikasi konstruksi ringan 


\section{METODE PENELITLAN}

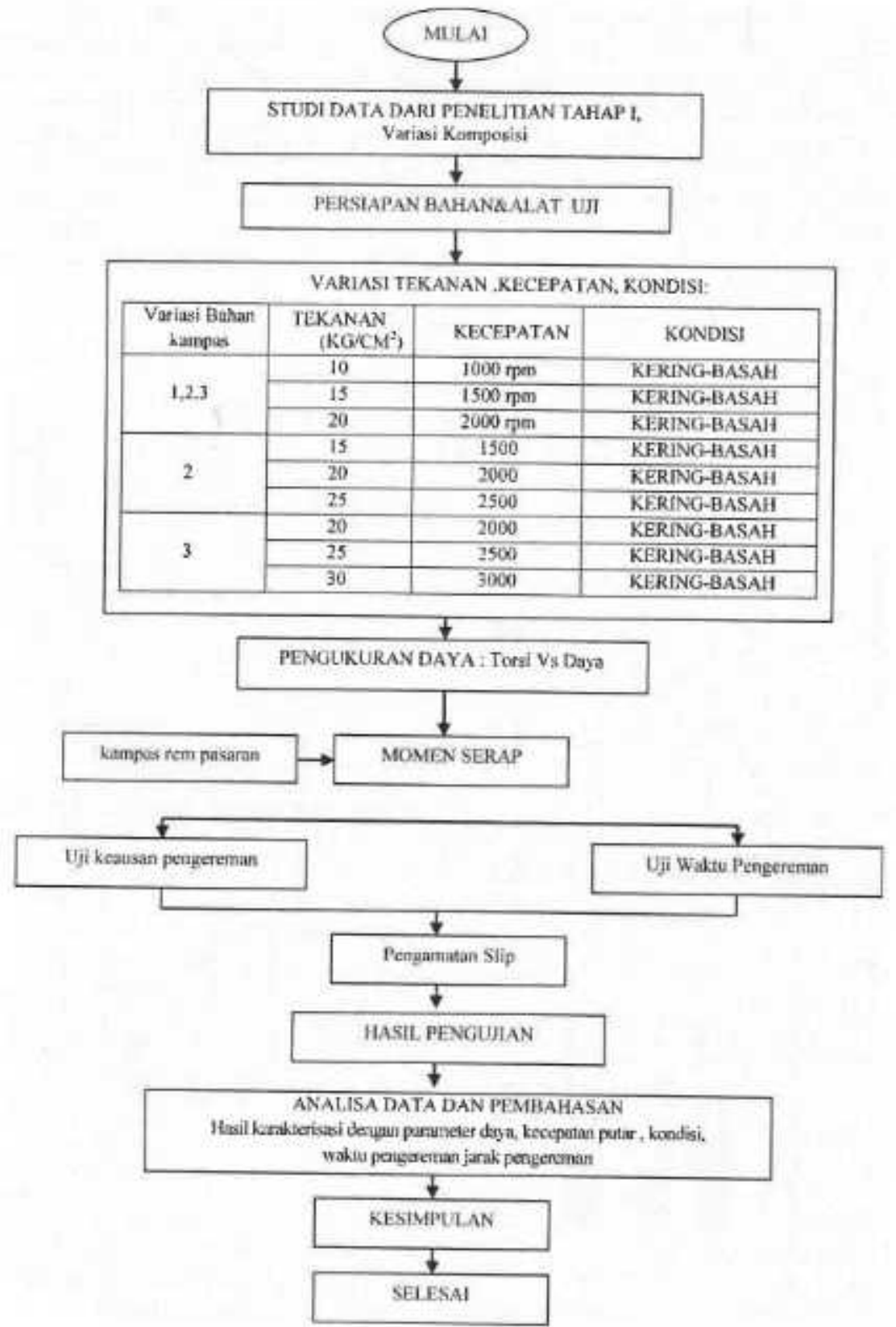

Gambar 1. Skema Diagram Alir Penelitian. 


\section{HASIL PENELITIAN}

Dengan menggunakan variasi komposisi dari serat bambu, fiber glass, serbuk aluminium (Al), dengan matriks polyester, dengan hasil terbaik kekerasan dan keausan pada komposisi komposisi sebesar $20 \%$ bonggol jagung +30 $\%$ fiber glass $+30 \%$ aluminium $(A l)+20 \%$ polyester, utuk dijadikan prototype kamaps rem sepeda motor,

\section{Alat Uji Dinamometer}

Alat ini untuk menguji torsi dan gaya yang mampu diserap rem, dengan penggerak motor listrik, dengan mengukur: daya listrik, dari tegangan dan anus yang terukur. Bila putaran bisa diukur dengan tachometer, maka torsi serap rem dapat dihitung. Dengan mengukur diameter drum, mika gaya gesek dapar diperoleh, selanjutnya bila tekanan bisa diukur,maka kofision geck rem dapar diperoleh, baik dalam kondisi kering dan kondisi basah. Dengin percobaan seperti tabel berikut.

Tabel 2. Variasi percobaan pada alat dinamometer.

Variasi Tekanan, Kecepatan, Kondisi:

\begin{tabular}{|c|c|c|c|}
\hline $\begin{array}{l}\text { BAHAN } \\
\text { KAMP }\end{array}$ & $\begin{array}{l}\text { TEKANAN } \\
\left(\mathrm{KG}^{\prime} \mathrm{CM}^{2}\right)\end{array}$ & $\begin{array}{l}\text { KECEPATAN } \\
\text { (mm) }\end{array}$ & KONDISI \\
\hline \multirow{3}{*}{1} & 10 & 1000 & KERING-BASAH AIR-BASAH OLI \\
\hline & 15 & 1500 & KERING-BASAH AIR-BASAH OLI \\
\hline & 20 & 2000 & KRRING-BASAH AIR-BASAH OLI \\
\hline \multirow{3}{*}{2} & 15 & 1500 & KERING-BASAH AIR-BASAH OLI \\
\hline & 20 & 2000 & KERING-BASAH AIR-BASAH OLI \\
\hline & 25 & 2500 & KERING-BASAH AIR-BASAH OEI \\
\hline \multirow{3}{*}{3} & 20 & 2000 & KERING-BASAH AIR-BASAH OU \\
\hline & 25 & 2500 & KERNG-BASAH AIR-BASAH OH \\
\hline & 30 & 3000 & KERING-BASAH AIR-BASAH OU \\
\hline
\end{tabular}

Hasil Pengujian

Pengujian Keausan Dengan Oghosi Wear Test

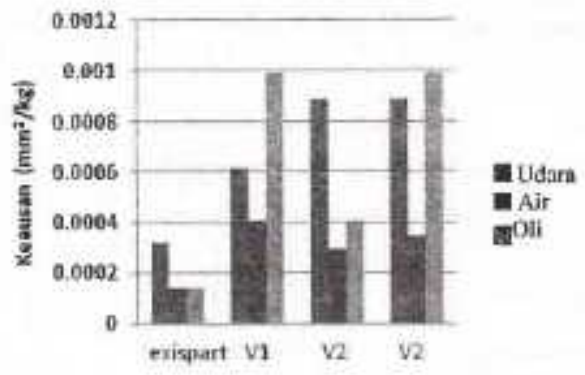

Gambar 2. Grafik Hasil Pengujian Keausan Oghosi Untuk berbagai Media Pembasahan Pengereman
Pengujian Keausan Dengan Wipro Test

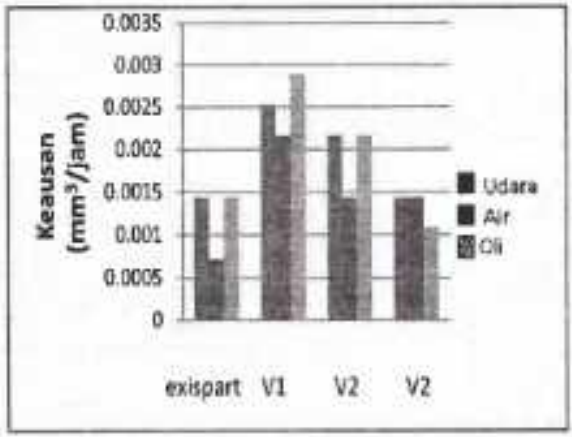

Gambar 3. Perbandingan Harga Keausan Wipro Untuk Berbagai Media Pembasahan 


\section{KESIMPULAN DAN SARAN}

\section{Kesimpulan}

Dari data hasil penelitian, maka dapat ditarik kesimpulan bahwa:

1. Untuk Pengujian Keausan Ogoshi pada kondisi kering, maka bahan kampas rem dengan Variasi 2 , metmpunyai nilai keausan yang ${ }^{2} / \mathrm{kg}$ ,yang sedikit lebih besar dari produk di pasaran dengan keausan sebesar $0.00014 \mathrm{~mm}^{2} /$ kg. Untuk Pengujian Keausan Ogoshi Kondisi basah dengan air, diperoleh bahwa, bahan kampas rem dengan Variasi 1 paling rendah keausannya yaitu sebesar $0,0062 \mathrm{~mm}^{2} /$ $\mathrm{kg}$, namun masih lebih tinggi sedikit dari bahan kampas rem pasaran ( cksipart) yaitu sebesar $0,0032 \mathrm{~mm}^{2} / \mathrm{kg}$

Pengujian Keausan Ogoshi Kondisi basah dengan oli, diperoleh bahwa, bahan kampas rem dengan Variasi 2 paling rendah keausannya yaitu sebesar $0,0003 \mathrm{~mm}^{2} / \mathrm{kg}$, namun masih lebih tingge sedikit dari bahan kampas rem pasaran yaitu sebesar $0,00014 \mathrm{~mm}^{2} / \mathrm{kg}$
2. Untuk Pengujian Keausan Wipro pada kondisi kering, maka bahan kampas rem dengan Variasi 3 , mempunyai nilai keausan yang paling rendah yaitu sebesar $0.00014 \mathrm{~mm}^{2} / \mathrm{kg}$, yang sama dari produk di pasaran dengan keausan sebesar $0.00014 \mathrm{~mm}^{2} / \mathrm{kg}$. Untuk Pengujian Keausan Wipro Kondisi basah dengan air, dipcroleh bahwa, bahan kampas rem dengan Variasi 2 dan 3 paling rendah keausannya yaitu sebesar $0,0014 \mathrm{~mm}^{2} / \mathrm{kg}$. namun masih lebih tinggi sedikit dari bahan kampas rem pasaran yaitu sebesar 0,0007 $\mathrm{mm}^{2} / \mathrm{kg}$

Pengujian Keausan Wipro Kondisi basah dengan oli, diperoleh bahwa, bahan kampas rem dengan Variasi 3 paling rendah keausannya yaitu sebesar $0,0011 \mathrm{~mm}^{2} / \mathrm{kg}$, namun masih lebih tinggi sedikit daribahan kampas rem pasaran yaitu sebesar $0,00014 \mathrm{~mm}^{2} / \mathrm{kg}$

\section{Saran}

DariKesimpulan dapat dirckomendasikan bahwa bahan kampas rem dengan variasi 1 atau 2 dapat dijadikan alternatif bahan kampas rem yang mendekati karakteristik di pasaran.

\section{DAFTAR PUSTAKA}

ASM Handbook, 1990. Friction Lubrication And Wear Technology. ASM International Volume 18, USA.

Blau J. Peter, Compasitions, Functions, and Testing of Friction Brake Materials and Their Additives, U.S. DEPARTMENT OF ENERGY, August 2001.

F. Thumier, 1993. Powder Metalurgy. Institute Of Material, London.

German, R.M., 1984. Powder Metallurgy Science. Metal Powder Industries Federation. Princeton, New Jersey.

Imam Setiyanto, Pramuko, 2009. Pengaruh Variasi Temperatur Sintering Terhadap Ketahanan Aus Bahan Rem Gesek Sepatu. Laporan Tugas Akhir Fakultas Teknik Mesin UMS, Agustus 2009, Surakarta.

Irfan, Pramuko, 2009, Pengaruh Variasi Tekanan Kompaksi Terhadap Ketahanan Kampas Rem Gesek Sepatu. Laporan Tugas Akhir Fakultas Teknik Mesin UMS, Agustus 2009, Surakarta. 
Kalpakjian, S., Schmid, Steven R., 2003, Mamufacturing Processes for Eingineering Materials, Fourth Edition, Illinois Institute of Technology, Chicago.

Niemantsverdriet J. W. Chorkendorff, 2000. Concepts Of Modern Catalysis and Kinetics, Denmark and Netheriands

Ogosht High Speed Universal Wear Testing Machine ( Type OAT-U). Instruction Manual. Tokyo Testing Machine MFG. Co.,ltd. Japan. 